\title{
Duplicação cromossômica de gramíneas forrageiras: uma alternativa para programas de melhoramento genético
}

\author{
Chromosome doubling of grasses: an alternative to plant breeding \\ Roselaine Cristina Pereira ${ }^{\mathrm{I}}$ Lisete Chamma Davide ${ }^{\mathrm{II}}$ Vânia Helena Techio" \\ Ana Luiza Oliveira Timbón
}

- REVISÃO BIBLIOGRÁFICA -

\section{RESUMO}

A obtenção artificial de genótipos com duplicação cromossômica em forrageiras busca maximizar características de interesse agronômico, como valor nutricional e produção de forragem, resistência a pragas e doenças, tolerância a estresses abióticos e restauração da fertilidade de híbridos estéreis. Outro objetivo da duplicação cromossômica é a geração de variabilidade genética em espécies apomíticas, por meio da duplicação cromossômica de acessos sexuais igualando a ploidia de modo a permitir a realização de cruzamentos e a obtenção de descendentes férteis. A indução de poliploidia é feita utilizando substâncias antimitóticas, sendo a colchicina a mais amplamente usada em plantas forrageiras. Entretanto, devido a sua toxicidade, outras substâncias como herbicidas e cafeína vem sendo empregadas com sucesso em gramíneas. A eficácia na obtenção de poliploides artificialmente depende de uma série de fatores exógenos, tais como as substâncias antimitóticas utilizadas, o tipo de explante, o tempo $e$ as condições de exposição e as concentrações dos antimitóticos. Esta revisão tem por objetivo apresentar os principais métodos usados para indução de poliploidia em gramíneas forrageiras e os avanços obtidos no melhoramento genético, a partir do uso de genótipos poliploidizados.

Palavras-chave: poliploidização, substâncias antimitóticas, colchicina, herbicidas, cafeína, explantes.

\section{ABSTRACT}

The artificial obtaining of duplicate genotypes aims to maximize forage characteristics of agronomic interest, such as nutritional value and forage production, resistance against pests and diseases, abiotic stress tolerance and fertility restoration in sterile hybrids. It also aims to obtain genetic variability in apomictic species through chromosome doubling of the sexual accesses by equaling the ploidy in order to allow crossings and the obtaining of fertile descendents. The polyploidy induction is made using antimitotic substances, and colchicine is the most widely used in forage. However, due to its toxicity, other substances such as herbicides and caffeine has been used successfully for grasses. The efficiency in obtaining the polyploidy artificially depends on various exogenous factors, such as the antimitotic substances used, the kind of explants, the time and the exposure conditions and the antimitotic concentrations. This review aims to present the main methods used to induce polyploidy in grasses and the progress obtained in genetic breeding by the use of artificially duplicate genotypes.

Key words: polyploidization, antimitotic substances, colchicine, herbicide, caffeine, explants.

\section{INTRODUÇÃO}

A indução da duplicação cromossômica é de interesse para os programas de melhoramento genético de plantas, sendo empregada com distintas finalidades para várias espécies. Metodologias eficientes de duplicação cromossômica podem contribuir para acelerar etapas dos programas de melhoramento e viabilizar o emprego de estratégias que não são possíveis naturalmente.

Devido à sua importância, alguns programas de melhoramento incluem a poliploidização como uma

'Departamento de Biologia (DBI), Universidade Federal de Lavras (UFLA), CP 3037, 37200-000, Lavras, MG, Brasil. E-mail: rcristinapereira@yahoo.com.br. Autor para correspondência.

"Departamento de Biologia, UFLA, Lavras, MG Brasil. 
de suas estratégias. Entre as suas inúmeras vantagens, destacam-se a possibilidade de ampliação da base genética, a restauração da fertilidade de híbridos interespecíficos, a obtenção de linhagens em curto espaço de tempo e a viabilização de cruzamentos quando os genótipos de interesse apresentam ploidias diferentes (BARBOSA et al., 2007; CAMPOS et. al., 2009; ISHIGAKI et al., 2009; SOUZA-KANESHIMA 2010). Para forrageiras, a obtenção de genótipos duplicados objetiva maximizar características de interesse agronômico, tais como valor nutricional e produção de forragem, distribuição da produção de forragem de acordo com o ciclo vegetativo, resistência a pragas e doenças, tolerância a estresses abióticos e restauração da fertilidade de híbridos estéreis (NAIR, 2004; CAMPOS et al., 2009). Outro objetivo é a geração de variabilidade genética em espécies apomíticas, por meio da duplicação de genótipos sexuais igualando a ploidia, de modo a permitir a realização de cruzamentos e a obtenção de descendentes férteis (PEREIRA et al., 2001; SOUZA SOBRINHO et al., 2009).

A indução de poliploidia pode ser feita utilizando substâncias antimitóticas, as quais atuam sobre as fibras do fuso acromático durante a divisão celular, impedindo sua polimerização ou promovendo a sua fragmentação, e assim não permitem a separação dos cromossomos na anáfase. Consequentemente, as células iniciam o ciclo celular seguinte com a quantidade de DNA duplicado.

Em espécies forrageiras, assim como para outras espécies, a colchicina é a substância mais usada para indução da poliploidia, tal como relatado para Brachiaria (ISHIGAKI et al., 2009; PEREIRA et al., 2010; SOUZA-KANESHIMA et al., 2010), Lolium (JONES \& HUMPREYS, 1993; PASAKINSKIENE, 2000; NAIR, 2004), Paspalum notatum (QUESENBERRY et al., 2010), Pennisetum (BARBOSA et al., 2007; CAMPOS et al., 2009) e Tripsacum (SALON \& EARLE,1998).

Embora forneça resultados satisfatórios, a colchicina é um alcaloide altamente tóxico e mutagênico, fato que tem estimulado a busca por drogas antimitóticas alternativas com eficácia similar ou superior à colchicina. Relatos de uso da cafeína para a indução de poliploidia em Hordeum vulgare (SCAGLIUS et al., 2009) e orizalina e trifluralina em Paspalum notatum (QUESENBERRY et.al., 2010) mostram-se promissoras para gramíneas.

Esta revisão tem por objetivo apresentar os principais métodos usados para indução de poliploidia em gramíneas forrageiras e os avanços obtidos no melhoramento genético, a partir do uso de genótipos poliploidizados.
Duplicação cromossômica no melhoramento genético de forrageiras

Objetivos e estratégias

A duplicação cromossômica artificial é utilizada nos programas de melhoramento genético com diferentes objetivos: - obter linhagens em curto espaço de tempo; - ampliar a variabilidade; - possibilitar cruzamentos entre plantas com ploidias distintas; restaurar fertilidade em híbridos intra e interespecífico; - permitir a transferência de genes entre indivíduos com diferentes níveis de ploidia e ampliar a expressão de características agronômicas de interesse.

O gênero Brachiaria inclui espécies importantes como B. ruziziensis $(2 \mathrm{n}=2 \mathrm{x}=18$ e sexual $) \mathrm{e}$ B. brizantha B. decumbens (ambas com $2 n=4 x=36$ e apomíticas) utilizadas em pastagens no Brasil. Todas as espécies apresentam vantagens e limitações para uso como forrageiras, assim é necessário que as características sejam combinadas em novas cultivares por meio de hibridações. Uma estratégia para explorar a variabilidade existente nos indivíduos apomíticos é a realização de cruzamentos artificiais com as plantas sexuais. Para viabilizar esses cruzamentos, é necessária a uniformização na ploidia dos genitores, a qual pode ser obtida por: haploidização das espécies apomíticas tetraploides ou duplicação do número cromossômico das diploides sexuais.

Resultados positivos para Brachiaria foram obtidos porFERGUSON\&CROWDER(1974), GOBBEetal. (1981), SWENNEetal.(1981).As cultivares MulatoIe Mulato II, lançadas pelo CIAT, são resultados dessa estratégia (SOUZA SOBRINHO et al., 2009). Do mesmo modo, a Embrapa Gado de Corte apresenta diversos híbridos interespecíficos em estado avançado de avaliações para o lançamento. Mais recentemente, foram identificados acessos diploides e sexuais de B. brizantha $\boldsymbol{B}$ B. decumbens no banco de germoplasma da Embrapa Gado de Corte (VALLE et al. 2008). Esses genótipos também foram submetidos a tratamentos visando à poliploidização para serem aproveitados dentro dos programas de melhoramento (PINHEIROetal.2008; SIMIONI\& VALLE, 2009).

Estratégias semelhantes vêm sendo empregadas em Tripsacum e Paspalum (LEBLANC, et al., 1995; QUESENBERRY et al., 2010). Em Paspalum, os acessos diploides e sexuais apresentam $2 n=2 x=20$ e os apomíticos tetraploides $2 n=4 x=40$. Em Tripsacum, as plantas sexuais e apomíticas apresentam $2 n=2 x=36$ e $2 n=4 x=72$, respectivamente. À semelhança da estratégia utilizada em Brachiaria, o objetivo é induzir a duplicação cromossômica nas espécies sexuais, o que torna possível explorar a variabilidade presente nas plantas apomíticas por meio de cruzamentos artificiais, bem como o estudo da herança da apomixia 
e aprimoramento da expressão de caracteres de interesse.

Em Lolium, a duplicação cromossômica tem sido empregada para potencializar caracteres de interesse agronômico e para restaurar a fertilidade de híbridos interespecíficos entre Lolium e Festuca (PASAKINSKIENE, 2000; NAIR, 2004). As espécies de Lolium se apresentam naturalmente nas formas diploides, L. perenne e L. multiflorum, $\operatorname{com} 2 n=2 x=14$. Nestes, a produção do autotetraploide objetiva aumentar caracteres de interesse agronômico como qualidade da forragem, resistência a doenças, uniformidade e estabilidade das populações. Quando o objetivo é melhorar a resistência a doenças e tolerância a frio, a estratégia adotada pelos melhoristas é a hibridação intergenérica com Festuca arundinaceae $(2 \mathrm{n}=4 \mathrm{x}=28)$. Nesse caso, são produzidos híbridos estéreis $(2 n=3 x=21)$ e a duplicação cromossômica é usada para restaurar a fertilidade desses híbridos (PASAKINSKIENE, 2000).

Em Pennisetum, a duplicação cromossômica objetiva a restauração da fertilidade de híbridos entre o milheto (P. glaucum, $2 \mathrm{n}=2 \mathrm{x}=14)$ e o capim elefante $(\boldsymbol{P}$. purpureum, $2 \mathrm{n}=4 \mathrm{x}=28$ ) e aumentar a expressão de caracteres de interesse (por exemplo, qualidade e quantidade de forragem, tamanho de sementes). A esterilidade desse híbrido $(2 n=3 x=21)$ constitui um fator limitante para os programas de melhoramento do capimelefante por inviabilizar a obtenção de descendentes férteis. Além disso, os produtores preferem forrageiras cultivadas por meio de sementes por facilitar o transporte e semeadura durante a implantação da pastagem. O sucesso dessa estratégia contribuirá, ainda, para o desenvolvimento da indústria de sementes que poderá incluir mais uma espécie forrageira nas opções para comercialização. Híbridos poliploidizados artificialmente no Brasil já constituem populações apresentando características agronômicas com potencial para o desenvolvimento de cultivares. Além disso, o uso desses poliploides artificiais em retrocruzamentos tem gerado raças cromossômicas tetra- e pentaploides, com potencial de uso no programa de melhoramento do capim-elefante.

Esses exemplos demonstram a contribuição do uso da duplicação cromossômica artificial com diferentes objetivos para os programas de melhoramento de gramíneas.

\section{Métodos e substâncias antimitóticas utilizadas}

A duplicação cromossômica em gramíneas forrageiras tem empregado metodologias in vivo e in vitro. Na metodologia in vivo, os explantes são imersos na solução antimitótica e, após a sua remoção, procede- se o plantio. Apesar de simples, a metodologia in vivo apresenta como desvantagem a necessidade de um espaço grande para a manutenção das plantas regeneradas e um controle mais efetivo contra pragas e doenças, entre outros fatores.

A metodologia in vitro é mais complexa e compreende outras etapas. O procedimento consiste no estabelecimento dos explantes in vitro e, em seguida, eles são submetidos ao tratamento com o agente antimitótico que, geralmente, é adicionado ao meio de cultura. Uma das desvantagens dessa metodologia está relacionada ao fato de que nem todas as espécies se estabelecem bem nas condições de cultivo in vitro. Por outro lado, dispõe-se de um controle maior sobre as condições do experimento, tais como: temperatura, luminosidade, nutrição, controle de patógenos, entre outros.

Independente da metodologia empregada, o estabelecimento de protocolos eficientes é dependente de vários fatores, tais como: substância antimitótica; tipo de explante; concentração dos antimitóticos e tempo de exposição dos explantes aos tratamentos e o genótipo selecionado.

Em forrageiras, a maioria dos poliploides artificiais foi obtida por meio de experimentos conduzidos in vitro. Em Pennisetum, Paspalum $e$ Tripsacum a duplicação tem sido feita in vitro, mas, em Brachiaria e Lolium, foram obtidos resultados positivos com ambas as metodologias (LEBLANC et al., 1995; PASAKINSKIENE, 2000; BARBOSA et al., 2007; SIMIONI \& VALLE, 2009; CAMPOS et al., 2009; ISHIGAKI et al., 2009; PEREIRA et al., 2010; QUESENBERRY et al., 2010).

Considerando que pode ocorrer a interação entre diversos fatores, existem dificuldades em se estabelecer uma metodologia eficiente e universal. Para cada espécie, é necessário testar a metodologia que oferece as melhores respostas.

A obtenção sintética de plantas poliploides requer a interferência no ciclo celular por variações na temperatura ou pelo uso de produtos químicos. Somente os fatores e/ou substâncias que atuam no final da fase $S$ e antes do início da citocinese apresentam potencial de induzir a poliploidização.

A maioria das substâncias antimitóticas é inibidora da metáfase, impedindo a organização/ polimerização dos microtúbulos (por exemplo: colchicina) ou promovendo sua ruptura (por exemplo: os carbamatos). Como os microtúbulos são essenciais para a correta migração polar dos cromossomos durante a anáfase, em consequência da ação dos antimitóticos, as células apresentarão o complemento cromossômico duplicado (Figura 1). 


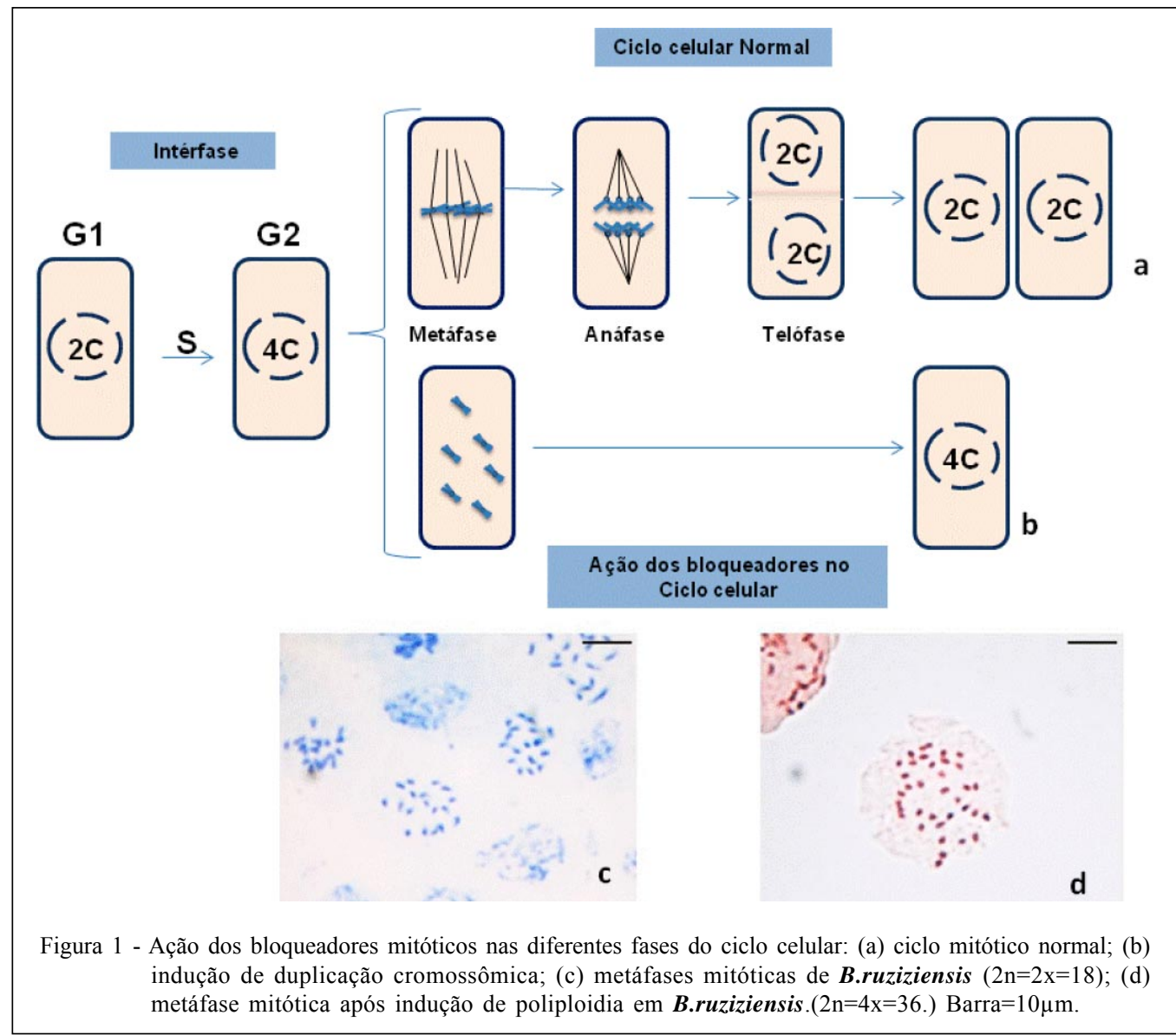

O antimitótico mais usado para indução da poliploidização é a colchicina, inclusive para gramíneas forrageiras. A colchicina é um alcaloide extraído de plantas de Colchicum autumnale (EIGSTI \& DUSTIN, 1955) e tem como vantagem não reduzir seu efeito na poliploidização com a autoclavagem, etapa necessária para os protocolos de duplicação in vitro (ZHANG et al., 2007). No entanto, em muitas espécies vegetais, a colchicina é muito tóxica e provoca efeitos secundários, tais como esterilidade, crescimento anormal, perdas ou rearranjos cromossômicos e mutações (LUCKETT, 1989).

Substâncias menos tóxicas, como o APM (Amiprophos-methyl), a cafeína, a orizalina e a trifluralina, apresentam efeitos similares ao da colchicina e estão sendo utilizados com sucesso para gramíneas forrageiras e outras espécies (SALON \& EARLE, 1998; SCAGLIUSI et al., 2009; QUESENBERRY et al., 2010).

Um dos problemas comumente encontrados no processo de poliploidização é a regeneração de plantas mixoploides, isto é, plantas que apresentam células com variações no número cromossômico ou na ploidia em um mesmo tecido ou entre órgãos de uma mesma planta. A mixoploidia ocorre porque o tratamento com o agente antimitótico age sobre as células dos explantes que estão em diferentes estágios do ciclo celular, resultando na desuniformidade do tecido. Essa variação no número cromossômico compromete a fertilidade e a estabilidade das plantas no campo, sendo indesejável sob o ponto de vista comercial e ou para fins de melhoramento genético.

O sucesso na indução da duplicação cromossômica também depende da eficiência e da toxicidade dos antimitóticos, que varia entre e dentro das espécies. Em Brachiaria, Lolium e Pennisetum, a duplicação cromossômica tem sido feita com colchicina em metodologias in vitro e in vivo. Para Brachiaria, foi observado que a porcentagem de plantas duplicadas variou de 3,9\% a 41\% (PINHEIRO et al., 2000; SIMIONI \& VALLE, 2009; ISHIGAKI et al., 2009; PEREIRA et al., 2010). Já em Lolium, a eficiência da duplicação cromossômica variou de 16 a 78\% (PASAKINSKIENE, 2000; NAIR, 2004) e, para Pennisetum, entre 8,5\% e 38\% (CAMPOS et al., 2009; BARBOSA et al., 2007).

Em Paspalum, QUESENBERRY et al. (2010) obtiveram tetraploides artificiais utilizando colchicina, trifuralina e orizalina in vitro. A porcentagem média de 
tetraploides induzidos para todos os tratamentos foi de $22 \%$, com média de $31 \%$ para orizalina, $24 \%$ para colchicina e $16 \%$ para trifluralina.

Essas informações mostram a necessidade de testes preliminares para o estabelecimento de um protocolo de duplicação eficiente para cada espécie em que se deseja utilizar a indução de poliploidia como ferramenta para estratégias de melhoramento.

Tipo de explantes

O tipo de explante utilizado no processo de indução de poliploidia também pode fornecer resultados diferenciados em resposta aos tratamentos utilizados e mostrar variações entre e dentro da espécie e do explante. Essas diferenças podem ocorrer devido à permeabilidade do tecido e à capacidade de transporte dos agentes antimitóticos (KERMANI et al., 2003; PETERSEN et al., 2003; ALLUM et al., 2007).

Em Brachiaria, a indução da duplicação foi feita em sementes, seedlings e segmentos basais (PINHEIRO etal., 2000; ISHIGAKI et al., 2009; PEREIRA et al., 2010). Os melhores resultados foram obtidos utilizando segmentos basais (41-50\%) e seedlings (31,3\%) (ISHIGAKI et al., 2009; PINHEIRO et al., 2000).

Em Lolium, foram empregados embriões e seedlings e a porcentagem de duplicação variou de 39,7 a $70 \%$ conforme NAIR (2004) e PASAKINSKIENE (2000), respectivamente. SALON \& EARLE (1998) e QUESENBERRY et al. (2010) utilizaram calos para induzir a duplicação em Paspalum e Tripsacum. Em Paspalum, a porcentagem de duplicação variou de 9 a 43\% e, em Tripsacum, de 15 a 52\%.

No gênero Pennisetum, para indução de duplicação cromossômica, foram empregados: meristemas, seedlings, plântulas e segmentos caulinares (BARBOSA et al., 2007; CAMPOS et al., 2009). A porcentagem de plantas hexaploides obtidas por BARBOSA et.al. (2007), usando colchicina em condições in vitro, foi de 19,5\% para seedling, 5,4\% para plântulas e $11,8 \%$ para segmentos caulinares. CAMPOS et al. (2009) obtiveram 8,5\% de hexaploides induzidos em Pennisetum utilizando seedling e metodologia in vitro. Com relação à indução da duplicação cromossômica em seedling in vivo, BARBOSA et al. (2007) conseguiram 8,3\% de hexaploides.

Concentração das substâncias antimitóticas e tempo de exposição dos explantes aos tratamentos

A concentração dos antimitóticos e o tempo de exposição dos explantes, bem como a interação entre ambos são informações importantes para garantir o sucesso do processo de indução de poliploidia
(DHOOGHE et al., 2011). O emprego de doses muito baixas tem se mostrado pouco eficiente, enquanto doses excessivamente altas mostram-se letais. A combinação entre doses altas do antimitótico e tempo de exposição prolongado podem redobrar o conteúdo de DNA, levando as células a atingir níveis de ploidia mais altos do que o desejado (ALLUM et al., 2007).

Em gramíneas forrageiras, a concentração dos antimitóticos e o tempo de exposição variam em função da espécie. Em Brachiaria, a indução de poliploidia tem sido feita exclusivamente com colchicina, variando a concentração de 0,01 a $0,1 \%$ e o tempo de exposição de 3 a 48h, utilizando metodologias in vivo e in vitro (PINHEIRO et al., 2000; ISHIGAKI et al., 2009; SIMIONI \& VALLE, 2009; PEREIRA et al., 2010). A melhor taxa de duplicação (41\%) foi obtida com o tratamento de colchicina $0,01 \%$ por $48 \mathrm{~h}$ (PINHEIRO et al., 2000).

Para Lolium, as concentrações de colchicina variaram de $0,1-0,4 \%$ e o tempo de exposição de 3 a 4h (PASAKINSKIENE, 2000; NAIR, 2004). Os melhores resultados foram obtidos com o tratamento de embriões in vitro, com colchicina $0,03 \%$ por $4 \mathrm{~h}$.

Em Pennisetum, as concentrações de colchicina empregadas foram de 0,05 e $0,1 \%$ e o tempo de exposição de 12 e 24h (BARBOSA et. al., 2007; CAMPOS et. al., 2009). Seedlings cultivados in vitro e tratados com colchicina a $0,1 \%$ por $24 \mathrm{~h}$ mostraram-se mais promissores na obtenção de poliploides.

Os tetraploides induzidos em Paspalum foram obtidos empregando colchicina $(313,626 \mathrm{e}$ $900 \mu \mathrm{M})$, orizalina $(5,10$ e $20 \mu \mathrm{M})$ e trifluralina $(5,10 \mathrm{e}$ $20 \mu \mathrm{M})$ por $48 \mathrm{~h}$ (QUESENBERRY et. al., 2010). A maior porcentagem (43\%) de plantas poliploidizadas foi obtida com o emprego da orizalina $(20 \mu \mathrm{M})$.

\section{Avaliação da poliploidização}

Os principais métodos de análise são a contagem cromossômica, a estimativa do conteúdo de DNA e a avaliação de características morfológicas e anatômicas (tamanho de células, diâmetro do grão de pólen, tamanho e densidade de estômatos).

A contagem do número cromossômico é um método confiável, pois determina o número exato de cromossomos de células individuais. No entanto, é laborioso e demorado, permitindo a avaliação de um número limitado de células, sendo desvantajoso quando se trata de análises de um grande número de plantas.

A análise de características morfológicas e anatômicas se dá pela observação do "efeito gigas", no qual os órgãos e células da planta aumentam de volume proporcionalmente ao aumento da quantidade 
de DNA. Entretanto, este tipo de análise nem sempre é eficiente e segura, devido à efeitos genéticos e ambientais, que podem ocasionar a classificação equivocada de determinados genótipos em relação ao nível de ploidia.

A observação de características anatômicas, como o tamanho dos estômatos, é simples e não requer equipamentos sofisticados. Plantas poliploidizadas tendem a ter estômatos maiores em relação às não duplicadas (CAMPOS et al., 2009; ISHIGAKI et. al., 2009; HODGSON et.al., 2010; QUESENBERRY et. al., 2010). Além do tamanho, a densidade estomática pode mudar com a poliploidização, pois, via de regra, as plantas poliploides apresentam menor densidade de estômatos.

O tamanho do grão de pólen também pode variar de acordo com o nível de ploidia (COHEN \& YAO 1996; CHAUVIN et al., 2005; DEWITTE et al., 2009). No entanto, essa característica raramente é usada para confirmar a poliploidização.

Portanto, os caracteres morfológicos podem ser usados como critério de seleção de poliploides induzidos, mas recomenda-se associar com as informações obtidas pelas contagens cromossômicas para se certificar da eficiência da duplicação e ausência de mixoploidia.

Para a verificação da ploidia em larga escala, tem sido realizada a análise do conteúdo de DNA nuclear utilizando a técnica de citometria de fluxo (DOLEZEL, 1997). Este é o método mais frequentemente empregado na detecção de poliploidia, seguido da contagem cromossômica e da combinação de ambas. A vantagem em relação à contagem cromossômica é permitir a avaliação do nível de ploidia de um grande número de plantas, de diferentes tipos de tecidos e analisar plantas em fase inicial do processo de duplicação cromossômica, uma vez que se trata de um método não destrutivo que utiliza pequenas quantidades de tecido jovem para análise.

Em gramíneas forrageiras, a verificação da poliploidia tem sido feita pela contagem cromossômica (PASAKINSKIENE, 2000; BARBOSA et al., 2007; SIMIONI \& VALLE, 2009) e também pela associação dessa metodologia com a determinação do conteúdo de DNA nuclear e análises cito-anatômicas (SALON \& EARLE, 1998; PINHEIRO et. al., 2000; NAIR, 2004; CAMPOS et. al., 2009; ISHIGAKI et. al., 2009; PEREIRA et. al., 2010).

\section{CONCLUSÃO}

A duplicação cromossômica é uma estratégia importante na produção de genótipos alterados para serem usados nos programas de melhoramento genético com finalidades distintas e/ou para estudos genéticos.

Normalmente, essas alterações resultam na superioridade dos poliploides em relação aos diploides quanto às características morfológicas, à adaptabilidade e à tolerância a estresses ambientais, proporcionando uma maior flexibilidade do genoma e permitindo uma melhor resposta às alterações ambientais. Entretanto, nem sempre as plantas poliploidizadas são estáveis sob o ponto de vista genético e fenotípico, sendo necessário o monitoramento genético e citogenético desses indivíduos para uma melhor compreensão desse fenômeno e para garantir a sua utilização comercial.

Com relação à técnica de duplicação cromossômica, há um grande número de fatores e interações que interferem em sua eficiência, o que torna necessário a realização de testes preliminares para auxiliar no estabelecimento de um protocolo eficiente para cada espécie.

Os programas de melhoramento genético de espécies forrageiras cultivadas no Brasil utilizam a indução da poliploidia como uma das estratégias para obtenção de genótipos superiores. Há cultivares comercializadas no Brasil que foram geradas com o auxílio da duplicação cromossômica em diferentes espécies forrageiras e algumas outras em fase final de avaliações para o lançamento.

\section{AGRADECIMENTOS}

À Fundação de Amparo à Pesquisa do Estado de Minas Gerais (FAPEMIG), pela concessão de bolsa de pós doutorado para primeira autora; ao Conselho Nacional de Desenvolvimento Científico e Tecnológico (CNPq), pelo suporte financeiro à pesquisa e aos pesquisadores Dr. Fausto de Souza Sobrinho (Embrapa Gado de Leite, Juiz de Fora-MG) e a Dra. Andrea Mittelmann (Embrapa Gado de Leite, Juiz de ForaMG e Embrapa Clima Temperado, Pelotas-RS), pela leitura crítica desse trabalho.

\section{REFERÊNCIAS}

ALLUM, J.F. et al. Chromosome doubling in a Rosa rugosa Thunb. hybrid by exposure of in vitro nodes to oryzalin: the effects of node length, oryzalin concentration and exposure time. Plant Cell Report, v.26, n.11, p.1977-1984, 2007. Disponível em: <http://www.springerlink.com/content/ h455571723384477/>. Acesso em: 18 jul. 2011. doi: 10.1007/ s00299-007-0411-y.

BARBOSA, S. et al. Duplicação cromossômica de híbridos triplóides de capim elefante e milheto. Bragantia, v.66, n.3, p.365-372, 2007. Disponível em: <http://redalyc.uaemex.mx/ pdf/908/90866301.pdf $>$. Acesso em: 18 jul. 2011. ISSN:16784499 . 
CAMPOS, J.M.S. et al. In vitro induction of hexaploid plants from triploid hybrids of Pennisetum purpureum and Pennisetum glaucum. Plant Breeding, v.128, n.1, p.101-104, 2009. Disponível em: <http://onlinelibrary.wiley.com/doi/10.1111/ j.1439-0523.2008.01546.x/full>. Acesso em: 18 jul. 2011. doi: $10.1111 /$ j.1439-0523.2008.01546.x.

CHAUVIN, J.E. et al. In vitro chromosome doubling in tulip (Tulipa gesneriana L.). Journal of Horticultural Science and Biotechnology, v.80, p.693-698, 2005.

COHEN, D.; YAO, J.L. In vitro chromosome doubling of nine 'Zantedeschia' cultivars. Plant Cell Tissue Organ Culture, v.47, n.1, p.43-49, 1996. Disponível em: <http:// www.ingentaconnect.com/content/klu/ticu/1996/00000047/ 00000001/00121113>. Acesso em: 18 jul, 2011.

DEWITTE, A. et al. Occurrence of viable unreduced pollen in a Begonia collection. Euphytica, v.168, n.1, p.81-94, 2009. Disponível em: <https://springerlink3.metapress.com/content/ a $42 \mathrm{r} 44 \mathrm{n} 102 \mathrm{gh} 5500 / \mathrm{res}$ o u c e - s e cured/ ? t arget $=$ f u $11 \mathrm{text}$. pdf \& s id $=1 \mathrm{bt} 1 \mathrm{nol} 2 \mathrm{bf} 1 \mathrm{mu}$ gb55uoore $5 \mathrm{q} 3 \& \mathrm{sh}=\mathrm{www}$. springerlink.com $>$. Acesso em: 18 jul. 2011. doi: 10.1007/s10681-009-9891-x.

DOLEZEL, J. Application of flow cytometry for the study of plants genomes. Journal of Applied Genetics, v.38, n.3, p.285-302, 1997.

DHOOGHE, E. et al. Mitotic chromosome doubling of plant tissues in vitro. Plant Cell Tissue Organ Culture, v.104, n.3, p.359-373, 2011. Disponível em: <http:// www.springerlink.com/content/w617x75227700134/>. Acesso em: 17 jul. 2011 . doi: 10.1007/s11240-010-9786-5.

EIGSTI, O.; DUSTIN, P. Colchicine in agriculture, medicine, biology, chemistry. Ames: Iowa University, 1955. 441p. Disponível em: <http://www.archive.org/details/ colchicineinagri00eigs $>$. Acesso em: 17 jul. 2011.

FERGUSON, J.E.; CROWDER, L.V. Cytology and breeding behavior of Brachiaria ruziziensis Germain et Evrard. Crop Science, v.14, n.6, p.893-895, 1974. Disponível em: <http:// link.periodicos.capes.gov.br/sfxlc13?url_ver=Z39.882004\&url_ctx_fmt $=$ infofi/fmt:kev:mtx:ctx\&ctx_enc=info:ofi/ enc:UTF-8\&ctx_ver=Z39.88-2004\&rfr_id=info:sid/ sfxit.com:azlist\&sfx.ignore_date_threshold $=1 \&$ rft.object_id $=954925393356 \&$ svc.fulltext $=$ yes $>$. Acesso em: 17 jul. 2011. doi:10.2135/cropsci1974.0011183X001400060036x.

GOBBE, J. et al. Diploïdes naturels et autotétraploïdes induits chez Brachiaria ruziziensis Germain et Evrard: critères d'identification. Agronomy Tropical, v.36, p.339-346, 1981.

HODGSON, J.G. et al. Stomatal vs. genome size in angiosperms: the somatic tail wagging the genomic dog? Annals of Botany, v.105, n.4, p.573-584, 2010. Disponível em: <http:// aob.oxfordjournals.org/content/105/4/573.abstract $>$. Acesso em: 17 jul. 2011 . doi: $10.1093 / \mathrm{aob} / \mathrm{mcq} 01$.

ISHIGAKI, G. et al. Induction of tetraploid ruzigrass (Brachiaria ruziziensis) plants by colchicine treatment of in vitro multipleshoot clumps and seedlings. Grassland Science, v.55, n.3, p.164 170, 2009. Disponível em: <http://onlinelibrary.wiley.com/doi/ 10.1111/j.1744-697X.2009.00153.x/pdf.>. Acesso em: 17 jul. 2011. doi: 10.1111/j.1744-697X.2009.00153.x.
JONES, M.L.; HUMPHREYS, M.O. Progress in breeding interspecific hybrid ryegrasses. Grass and Forage Science, v.48, n.1, p.18-25, 1993. Disponível em: <http://onlinelibrary.wiley.com/ doi/10.1111/j.1365-2494.1993.tb01832.x/pdf.>. Acesso em: 18 jul. 2011. doi: 10.1111/j.1365-2494.1993.tb01832.x.

KERMANI, M.J. et al. Oryzalin-induced chromosome doubling in Rosa and its effect on plant morphology and pollen viability. Theoretical and Applied Genetics, v.107, n.7, p.1195-1200, 2003. Disponível em: <http://www.springerlink.com/content/ 03dawa1chbvu285k/>. Acesso em: 17 jul. 2011. doi: 10.1007/ s00122-003-1374-1.

LEBLANC, O. et al. Chromosome doubling in Tripsacum: the production of artificial, sexual tetraploid plants. Plant Breeding, v.114, n.3, p.226-230, 1995. Disponível em: <http:/ / onlinelibrary.wiley.com/doi/10.1111/j.14390523.1995.tb00798.x>. Acesso em: 17 jul. 2011. doi:10.1111/ j.1439-0523.1995.tb00798.x.

LUCKETT, D. Colchicine mutagenesis is associated with substantial heritable variation in cotton. Euphytica, v.42, n.1-2, p.177-182, 1989. Disponível em: <http://www.springerlink.com/ content/j226078w0653571n/>. Acesso em: 17 jul. 2011. doi: 10.1007/BF00042630.

NAIR, R.M. Developing tetraploid perennial ryegrass (Lolium perenne L.) populations. New Zealand Journal of Agricultural Research, v.47, n.1, p.45-49, 2004. Disponível em: <http:// w w w.tandfon line.com/doi/abs/10.1080/ 00288233.2004.9513569\#preview>. Acesso em: 18 jul. 2011. doi: $10.1080 / 00288233.2004 .9513569$.

PASAKINSKIENE, I. Culture of embryos and shoot tips for chromosome doubling in Lolium perenne and sterile hybrids between Lolium and Festuca. Plant Breeding, v.119, n.2, p.185-187, 2000. Disponível em: <http://link.periodicos.capes.gov.br/ sfxlc13?url_ver=Z39.88-2004\&url_ctx_fmt $=$ infofi/ fmt:kev:mtx:ctx\&ctx enc=info:ofi/enc:UTF$8 \& \mathrm{ctx}_{-}$ver $=$Z $39.88-\overline{2} 004 \& \mathrm{rfr} \mathrm{rd}_{-} \mathrm{info:sid/}$ sfxit.com:azlist\&sfx.ignore_date_threshold $=1 \&$ rft.object_id=954925488804\&svc.fulltext $=$ yes $>$. Acesso em: 18 jul. 2011. doi: 10.1046/j.1439-0523.2000.00484.x.

PEREIRA, R.C. et al. Duplicação cromossômica em Brachiaria ruziziensis. In: CONGRESSO BRASILEIRO DE GENÉTICA, 56., 2010, Guarujá, SP. Anais... Ribeirão Preto: SBG, 2010. ISBN 978-85-89109-06-2.

PEREIRA, A.V. et al. Melhoramento de forrageiras tropicais. In: NASS, L.L. et al. Recursos genéticos e melhoramento de plantas. Rondonópolis: Fundação Mato Grosso, 2001. Cap.18, p.549-602.

PETERSEN K.K. et al. Colchicine and oryzalin mediated chromosome doubling in different genotypes of Miscanthus sinensis. Plant Cell Tissue Organ Culture, v.73, n.2, p.137146, 2003. Disponível em: <http://www.springerlink.com/ content/r78pg170214506v7/.>. Acesso em: 18 jul. 2011. doi: 10.1023/A: 1022854303371 .

PINHEIRO, A.A. et al. Duplication of the chromosome number of diploid Brachiaria brizantha plants using colchicine. Plant Cell Report, v.19, n.3, p.274-278, 2000. Disponível em: $<$ http://www.cabdirect.org/abstracts/20001608929.html. $>$. Acesso em: 18 jul. 2011. doi: 10.1007/s002990050011. 
QUESENBERRY, K.H. et al. Doubling the chromosome number of bahiagrass via tissue culture. Euphytica, v.17, n.1, p.4350(8), 2010. Disponível em: <http://www.ingentaconnect.com/ content/klu/euph/2010/00000175/00000001/00000165> Acesso em: 18 jul. 2011. doi: 10.1007/s10681-010-0165-4.

SALON, P.R.; EARLE, E.D. Chromosome doubling and mode of reproduction of induced tetraploids of eastern gamagrass (Tripsacum dactyloides L.). Plant Cell Report, v.17, n.11, p.881-885, 1998. Disponível em: <http://ddr.nal.usda.gov/ bitstream/10113/26446/1/IND21972759.pdf>. Acesso em: 18 jul. 2011 .

SCAGLIUS, S.M. et al. Estudos preliminares sobre o efeito da cafeína na duplicação cromossômica em plantas haplóides de cevada (Hordeum vulgare L.). Embrapa, documentos Online, ISSN: 1518-6512, 109, novembro, 2009. Disponível em: <http://www.cnpt.embrapa.br/biblio/do/p_do109.pdf $>$. Acesso em: 18 jul. 2011

SIMIONI, C.; VALLE, C.B. Chromosome duplication in Brachiaria (A. Rich.) Stapf allows intraspecific crosses. Crop Breeding and Applied Biotechnology, v.9, n.4, p.328-333, 2009. Disponível em: <http://www.scielo.br/scielo.php?pid=S198470332011000100006\&script $=$ sci_arttext $>$. Acesso em: $18 \mathrm{jul}$. 2011. doi: 10.1590/S1984-70332011000100006.
SOUZA-KANESHIMA, A.M. et al. Meiotic behaviour in the first interspecific hybrids between Brachiaria brizantha and Brachiaria decumbens. Plant Breeding, v.129, n.2, p.186-191, 2010 Disponível em: < http://ukpmc.ac.uk/abstract/AGR/IND44354520/ reload $=0$; jsessionid $=E 5 F 1 E 4 A 8189072 A 5 B 15 A 71 F 4213 E 0 C 8 D . j v m 4>$. Acesso em: 18 jul. 2011. doi: 10.1111/j.1439-0523.2009.01674.x.

SOUZA SOBRINHO, F. de et al. Melhoramento de gramíneas forrageiras na EMBRAPA Gado de Leite. In: SIMPÓSIO DE FORRAGICULTURA E PASTAGENS, 7., 2009, Lavras. Anais... Lavras: UFLA, 2009. p.98-111.

SWENNE, A. et al. Induction par la colchicine de formes autotétraploïdes chez Brachiaria ruziziensis Germain et Evrard (Graminée). Agronomie Tropicale, v.36, n.2, p.134-141, 1981 .

VALLE, C. B. et al. Melhoramento genético de Brachiaria. In: Resende, R. M. S. et al. Melhoramento Genético de Forrageiras Tropicais. Campo Grande: Embrapa Gado de Corte1, 2008. p.13-53.

ZHANG, J. et al. Obtaining autotetraploids in vitro at a high frequency in Citrus sinensis. Plant Cell Tissue Organ Culture, v.89, n.2-3, p.211-216, 2007. Disponível em: <http:/ /www.aseanbiotechnology.info/Abstract/21026814.pdf >. Acesso em: 18 jul. 2011. doi:10.1007//s1 1240-007-9240-5. 